\title{
Intervención del profesional del trabajo social con personas jóvenes y adultas con alguna discapacidad
}

\author{
Social work professional intervention with \\ young people and adults with disabilities
}

\author{
CECILIA GUADALUPE LIMÓN AGUIRRE \\ Técnica Académica del Departamento de Sociedad y Cultura de El Colegio de la Frontera Sur, (México) \\ climon@ecosur.mx / https://orcid.org/0000-0003-3386-0894 \\ JOSÉ MARÍA DUARTE CRUZ \\ Profesor Investigador Cátedra CONACYT - Universidad Autónoma Metropolitana, Departamento de \\ Política y Cultura, (México). duartecruz2911@hotmail.com / https://orcid.org/0000-0002-0235-1838
}

\begin{abstract}
Resumen: Esta investigación analiza los tipos de intervención del profesional de trabajo social con jóvenes y adultos que presentan alguna discapacidad. Se desarrolló en una asociación civil en Chiapas, México, mediante un abordaje cualitativo. Los hallazgos señalan que el modelo de la diversidad, centrado en el respeto, valoración de los derechos humanos, puede encaminarlos a procesos de resiliencia de largo plazo. La intervención debe tener presente el contexto histórico, social, familiar, económico, cultural y los aspectos biológicos del ser humano; además, concebir a estas personas como individuos con derechos, sentimientos, motivaciones y capacidades. Todo en su conjunto coadyuvará en la mejora de sus condiciones de vida y su integración en la sociedad.
\end{abstract}

Palabras claves: Trabajo Social, Discapacidad, Diversidad, Resiliencia.

\begin{abstract}
Summary: This research analyzes the types of social work professional intervention with young people and adults with disabilities. It was developed in a civil association in Chiapas, Mexico, using a qualitative approach. The findings indicate that the diversity model, focused on respect and valuation of human rights, can guide them to long-term resilience processes. The intervention must take into account the historical, social, family, economic, cultural context and the biological aspects of the human being; Furthermore, conceive of these people as individuals with rights, feelings, motivations, and abilities. Everything as a whole will contribute to the improvement of their living conditions and their integration in society.
\end{abstract}

Key words: Social Work, Disability, Diversity, Resilience. 


\section{INTRODUCCIÓN}

Reflexionar sobre los ámbitos de intervención del trabajo social es una tarea inacabada. Existen problemas relacionados con la búsqueda de identidad profesional y el desempeño de su rol (Celia, 2009); hay marcos y presupuestos teóricos no organizados; divergencia de conceptualizaciones, modelos y experiencias prácticas; rupturas entre la academia y el trabajo profesional y desplazamiento de lo social como centro de su quehacer (Tello, 2014; De Munford y Bennie, 2015). Cada área o campo de intervención presenta retos, desde enfoques, estilos, prioridades u ópticas, hasta la diversidad de atención en ámbitos vulnerables o de exclusión como el trabajo social con personas sin hogar, con alguna discapacidad, migrantes, consumidores de drogas, adultos mayores o jóvenes delincuentes (Fernández, 2017).

Muchas interrogantes aún se plantean sobre la cientificidad y los niveles de operar de los tipos de intervención en trabajo social. Como en otras ciencias sociales, las teorías guían, orientan y determinan el camino a seguir, sobre todo en el trabajo diario donde se contrasta la diada teoría-práctica. El trabajo social como ciencia y praxis debe compilar, revisar y actualizar constantemente sus modelos teóricos y de intervención, para hacer frente a los cambios y transformaciones sociales, si se desea desarrollar una acción profesional que abandere los principios de eficacia, eficiencia y calidad (Fernández, 2017).

Esta investigación analiza mediante un abordaje cualitativo, la gama de áreas y oportunidades de intervención del profesional de trabajo social en una asociación civil que atiende a jóvenes y adultos con alguna discapacidad; indaga sobre su modelo de intervención, cómo potencia y apoya a sus beneficiarios para que logren la resiliencia. De igual forma se examinan los significados, sentimientos y aprendizajes/ cambios de quienes integran la asociación y al final se presentan propuestas específicas de intervención.

\section{Discapacidad y trabajo social}

El tema de la discapacidad y concretamente su definición, sigue en debate (Schalok, 1999). Desde hace décadas hay progresos y mejoras en muchos sentidos: el reconocimiento de sus derechos, la madurez de las organizaciones y de los profesionales, el compromiso de los gobiernos, las respuestas de apoyo social, las crecientes iniciativas, programas, centros y servicios que dan respuestas diversificadas y especializadas a las necesidades de la población que presenta limitaciones de algún tipo (Verdugo, 2009).
El papel de las personas con discapacidad y de los organismos internacionales por superar obstáculos históricos relacionados con su definición han sido fundamentales para incorporar la propia percepción de las personas involucradas; sin embargo, aún no existe un consenso en cómo referirse a ellos, aunque las expresiones más aceptadas son personas con discapacidad o con alguna discapacidad. De Lorenzo (2014) define discapacidad como aquella limitación o limitaciones que presentan algunas personas para desarrollar determinadas actividades. Estas restricciones pueden tener distintas dimensiones de tipo físico, psíquico, sensorial, intelectual o mental; cada una puede manifestarse de diferentes maneras y en distintos grados.

Autores como Barton (1998); Abberley (2008); Muyor (2011), Fernández (2017) y otros, señalan que las personas que viven en contextos de pobreza o de algún tipo de privación tienen mayor riesgo de adquirir una discapacidad, como resultado de carencias en la atención sanitaria, enfermedades o deficiencias no prevenidas o tratadas a tiempo; a su vez, la discapacidad es un factor de exclusión, ya que estas personas no tienen las mismas oportunidades de trabajo y acceso a servicios sociales, salud, educación, entre otras.

Distintos trabajos de investigación han planteado una relación bidireccional entre discapacidad y exclusión social (Barton, 1998; Córdoba, 2008; Pantano, 2010; Muyor, 2011); muchas personas con discapacidad son víctimas de arquetipos que los llevan a sufrir discriminación permanente, aislamiento e imposición de restricciones sociales que les impide su desarrollo en el ámbito personal, familiar, social, educativo, económico, profesional, cultural, entre otros. Barton (1998) señala que al ser personas discriminadas, pueden experimentar vulnerabilidad y agresiones injustas.

"La discapacidad surge del fracaso de un entorno social estructurado a la hora de ajustarse a las necesidades y las aspiraciones de la ciudadanía con carencias, más que de la incapacidad de las personas con discapacidad para adaptarse a las exigencias de la sociedad" (Muyor, 2011:10).

Pantano, Barton y Gómez (en Córdoba, 2008) mencionan que la discapacidad es producida porque en el entorno social no existen los medios y condiciones de igualdad para acceder a las mismas oportunidades que tienen los demás, a cambio les imponen barreras que no posibilitan desarrollarse y potenciarse como ciudadanos "normales". De allí que la discapacidad tiene un fuerte vínculo con lo social y se agudiza por el entorno y las actitudes sociales hostiles, pues se les 
excluye de la participación en la sociedad (Pantano, 2010).

En resumen, una persona con alguna discapacidad no solo es aquella que presenta una determinada deficiencia física o enfermedad, sino aquella que dado un estado de salud y características del entorno (físicas o de actitudes), ve afectada su capacidad para realizar actividades cotidianas (Malo, 2003; López y Seco, 2005). Estas personas son vulnerables a distintas problemáticas asociadas a sus limitaciones y a cómo son vistas en la sociedad.

\section{Intervención, atención a la diversidad y resiliencia}

Los principios fundamentales del trabajo social están fundamentados en la no discriminación, en los derechos humanos, el respeto a la diversidad, la equidad y la justicia; de tal manera que en cada abordaje profesional se debe procurar -en la medida de lo posible-, el bienestar de cada quien (Escartín, 1998; Ortega, 2015). La intervención del trabajo social es vista como una forma consciente y planificada de acciones con propuestas metodológicas que proporcionan a individuos, familias y grupos la orientación necesaria para contrarrestar sus necesidades y problemas. El objetivo es ofrecer espacios, ser mediador, motivador, líder, guía y ayudarles a encontrar soluciones a situaciones que impiden su bienestar; para ello, debe basarse en el diagnóstico, tratamiento y evaluación. Barranco (2004), considera que la función profesional del trabajo social es:

"la acción organizada y desarrollada por los trabajadores sociales con las personas, grupos y comunidades, con objetivos que están orientados a superar los obstáculos que impiden avanzar en el desarrollo humano y en la mejora de la calidad de vida de la ciudadanía. Además, la intervención profesional se basa en los fundamentos éticos, epistemológicos y metodológicos del trabajo social desde un enfoque global, plural y de calidad" (79).

Ander-Egg (2008) señala que los objetivos específicos y modos concretos de intervenir deben estar sujetos a las características y al contexto de la realidad de las personas, así como al modelo de intervención. Por lo tanto, el objeto, objetivos y la ética del trabajo social estarán orientados hacia las personas en interacción con el entorno social, la promoción del desarrollo humano y la mejora de la calidad de vida. Tomando en cuenta que las personas forman parte de un contexto socio-histórico, económico, político y cultural, el profesional del trabajo social debe partir de un enfoque global, sistémico y plural.
En el ámbito de las asociaciones civiles y en aquellas que ofrecen servicios de bienestar social, la intervención en el trabajo social debe enfocarse desde la calidad integrada, es decir: calidad de vida' ${ }^{1}$, de servicio y de vida laboral.

"la calidad integrada en las organizaciones de servicios sociales de bienestar social puede contribuir a potenciar en las mismas la imagen poliédrica de la igualdad de oportunidades para toda la ciudadanía, la transparencia, la responsabilidad social, la orientación ecológica, la eficacia, la eficiencia y la calidez humana" (Barranco, 2004:100).

Estrada (2010) y Humphrey (2013) coinciden que la calidad integrada puede contribuir a estrategias concretas basadas en la filosofía, valores y principios defendidos desde el trabajo social. La intervención entra para configurar una doble condición: como objeto de conocimiento y como objeto de acción. Corvalán (1996) identifica dos tipos de intervención social, la caritativo-asistencial y la sociopolítica; la primera tiene que ver con un conjunto de acciones o quehaceres de beneficencia. La intervención sociopolítica es más efectiva, ya que es crítica, el apoyo es firme y se utilizan metodologías, estrategias y modelos con sustento teóricos y prácticos (Bermúdez, 2011):

"el carácter sociopolítico de una intervención social está dado por la concepción de la misma en torno a objetivos societales mayores y relacionados con el funcionamiento del modelo de desarrollo de una sociedad, especialmente en términos de situarse explícitamente como un apoyo o como una crítica al mismo" (Corvalán, 1996:4).

En el ámbito de la intervención en trabajo social existen cuatro modelos o formas de tratamiento social para las personas con discapacidad, según Palacios y Romañach (2006): el modelo de prescindencia, el médico-rehabilitador, el social y el de la diversidad; este último se basa en los derechos humanos y considera esencial lograr la plena dignidad y participación social de las personas que son discriminadas por su diversidad funcional procurando que tengan igualdad de oportunidades. Rescata las capacidades en vez de acentuar las discapacidades. Los principios básicos de este modelo y que están en consonancia con el trabajo social son: dignidad, libertad, autonomía, integridad, respeto, derecho, disfrute, goce, ejercicio en condiciones de igualdad, diversidad humana y resiliencia (Palacios y Romañach, 2006, en Muyor, 2011).

1 Es un estado deseado de bienestar personal que es multidimensional; tiene propiedades éticas, universales y emicas, ligadas a la cultura, tiene componentes objetivos y subjetivos; y está influenciada por factores personales y ambientales (Schalock y Verdugo, 2007:2). 
Un concepto de gran importancia para esta investigación es el de resiliencia. Suárez, (2003) la define como un "proceso complejo que implica la capacidad de un sistema -o personas- para recuperarse de perturbaciones, que surje fortalecida de ellas y transforma positivamente el entorno". En el plano de la discapacidad, este concepto indica que las personas pueden mostrar comportamientos resilientes si se trabaja sobre la perspectiva de las fortalezas y capacidades, promoviendo motivación constante desde diversos puntos de apoyo a nivel individual (por ejemplo, emocional), familiar, social, institucional, gubernamental u otros.

Desde la década de los 80, Germain y Gitterman presentaron la idea que los trabajadores sociales podrían utilizar las experiencias de la vida real para movilizar las fuerzas naturales de salud y crecimiento continuo de las personas. En los 90, Gilgun propuso que la resiliencia introducía al trabajo social un lenguaje teórico y práctico que fortalecía el desarrollo de investigaciones, programas, la práctica directa y la política social. Literaturas más recientes han revelado que el conocimiento de la perspectiva de resiliencia aporta ideas orientadas a estrategias de intervención altamente útiles en trabajo social (Villalba, 2011).

Las personas con discapacidad además de tener derechos poseen deberes igual que el resto de los ciudadanos. Si el objetivo es lograr la resiliencia, el profesional del trabajo social deberá concebir a cada persona como sujeto de acción y no como objeto que requiere caridad; su intervención debe enfocarse desde la calidad integrada, procurando acciones que utilicen metodologías y modelos teóricos que acentúen las capacidades y no sus discapacidades. Al conjugar estos elementos, esquematizamos una visión del trabajo social en la intervención enfocada a personas con discapacidad, que considera a los individuos con sus diferencias y semejanzas, como diferentes mas no carentes de capacidades y fortalezas.

En esta figura se coloca al trabajo social en el centro como el articulador del proceso; la intervención o conjunto de intervenciones es el campo propio de actuación; la persona con alguna discapacidad, comprendiendo que tiene derechos, deberes y capacidades que se deben potenciar, y finalmente la resiliencia, enfoque fundamentado empíricamente para la comprensión de la conducta humana (Badilla, 1999; Martínez, 2013).

\section{ASPECTOS GENERALES DE LA INVESTIGACIÓN}

\section{Problema}

Según el Censo y Conteo de Población y Vivienda (INEGI, 2010), el 6.6\% de los mexicanos tienen alguna discapacidad.

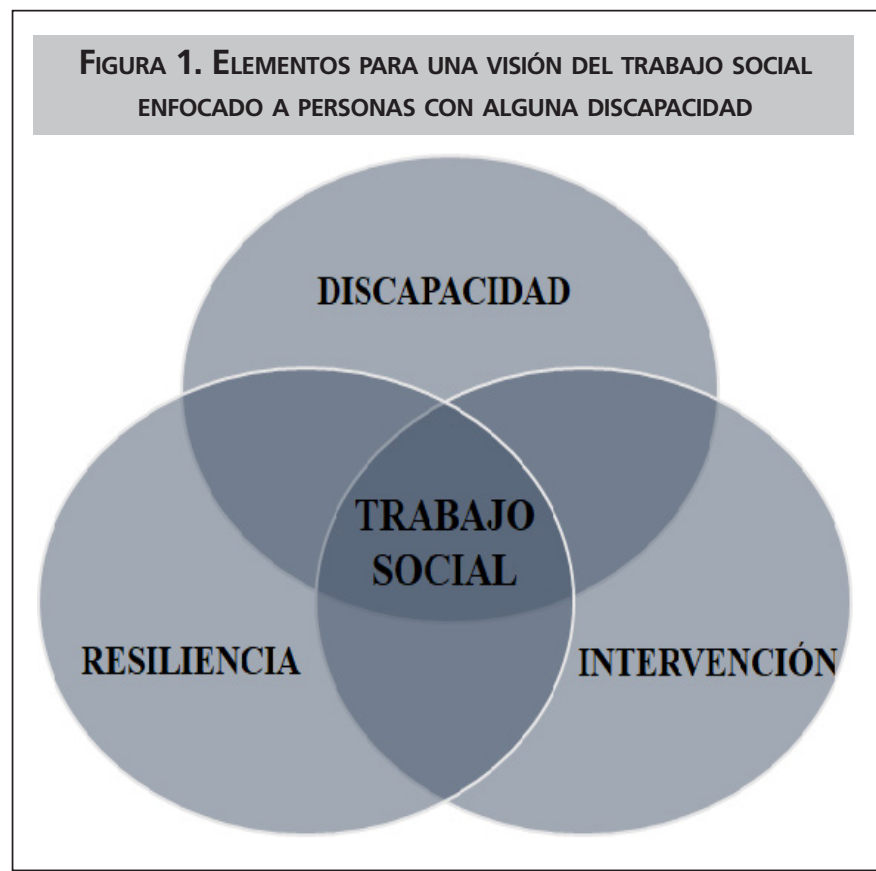

Fuente: elaboración propia.

La mayoría son adultos mayores de 60 años (48.2 \%), seguidos de personas entre 30 y 59 (32.8\%), los jóvenes de 15 a 29 (9.9 \%) y con menor porcentaje (9.1 \%) los niños/as y adolescentes de 0 a 14 años (INEGI, 2013:3).

Los estados con mayor proporción de personas con discapacidad son Tabasco, Oaxaca, Yucatán y Nayarit con porcentajes cercanos o por arriba del 10\%. En Chiapas es del $6.4 \%$ (INEGI, 2012:5), ubicándose entre los 16 estados debajo de la media nacional, presentando un $4.1 \%$ (INEGI, 2015b:3; 2016). Dentro de la entidad, el municipio de San Cristóbal de Las Casas (SCLC), donde se realizó esta investigación, muestra una prevalencia de $3.7 \%$ del total de sus habitantes (Anuario Estadístico y Geográfico de Chiapas, 2015a).

En México son pocas las intervenciones implementadas, las políticas públicas y sociales, los servicios, prestaciones y recursos destinados a la atención de personas con discapacidad, menos aún con jóvenes y adultos. Este grupo de población es especialmente vulnerable a la exclusión social por diversos motivos: distintas formas de pobrezas, insuficientes oportunidades para insertarse en el mercado laboral, discriminación, rechazo social, dependencia de algún familiar y/o cuidadores, entre otros. Esta población enfrenta muchas barreras, como el transporte público, las adaptaciones de los espacios, el lenguaje, la participación e inserción en la vida económica, política y social.

En el directorio nacional de asociaciones que atienden a esta población aparecen registradas cuatro organizaciones civiles en SCLC (INEGI, 2014); dentro de éstas, no hay ninguna 
para personas adultas con discapacidad. Existe una escuela gubernamental para niños y niñas que requieren educación especial, pero al concluir su escolaridad primaria o llegar a la adolescencia cuentan con pocos espacios académicos para desarrollarse; una limitante es la edad y otra que no les pueden ofrecer actividades complementarias para ayudarles e impulsar su independencia, quedando simplemente fuera del sistema educativo formal. Tienen pocas oportunidades para continuar su preparación a nivel medio y superior; tampoco existen coyunturas para participar en actividades físicas y deportivas, cursos de capacitación o formación para el trabajo, situaciones que agudizan sus condiciones de marginación.

\section{Características del lugar y población participante}

Chiapas se ubica en el sureste de la República mexicana; es un estado que acusa los mayores rezagos sociales y el menor grado de desarrollo económico del país (Villafuerte y García, 2014); ocupa el segundo lugar en el índice de marginación más alto (2.318), (CONAPO, 2017); la última posición del Índice de Desarrollo Humano (PNUD, 2015), con una gran cantidad de ayuntamientos enlistados en el grupo de los 100 municipios más pobres y marginados del país.

La ciudad de SCLC está ubicada en la región Altos de Chiapas, ha sido escenario de diversas reivindicaciones civiles, políticas, sociales y religiosas. Está considerada como la capital intercultural del estado. Según el censo de 2010 (INEGI), habi$\tan 185,917$ personas, de ellas el $55 \%$ se identifica como criollos y mestizos, aun cuando gran parte tienen la composición fenotípica característica de las etnias amerindias de la región maya y son hablantes de las lenguas tsotsil y tseltal.

En este municipio se ubica la asociación civil en la que se desarrolló la investigación; que nace en 2005 por la necesidad de brindar un servicio educativo a personas mayores de edad con alguna discapacidad, para que pudieran salir de sus casas, socializar y desarrollar nuevas habilidades. Inició el trabajo con clases de lectoescritura, talleres de manualidades y acompañamiento familiar en casas particulares. En 2008 la organización se constituyó legalmente y actualmente cuentan con un director general, un administrativo, dos docentes y un aproximado de seis voluntarios. Mantienen una asistencia de 20-25 jóvenes y adultos con diferentes discapacidades: visual, auditiva, motriz, síndrome de down, parálisis cerebral y autismo; la mayoría son de muy bajos recursos económicos y sus edades varían desde 18 a 51 años.

$\mathrm{AA}^{2}$ tiene como objetivo promover la autonomía e integración de jóvenes y adultos con alguna discapacidad dentro de su familia y su entorno sociocultural, así como lograr su autosuficiencia en la medida de sus posibilidades. Se trabaja de lunes a viernes de 9 a 14 horas, impartiendo clases de español, matemáticas, artes, manualidades, deporte, agroecología, gestión de negocios y terapias de rehabilitación física; también cuentan con tiempo y espacio de recreación. La intervención se desarrolla mediante cinco áreas: escolarización y acompañamiento, capacitación y orientación laboral, agroecología, fisioterapias y acompañamiento familiar.

Los proyectos sustentables como el huerto, la cafetería y tienda de productos elaborados por ellos mismos con materiales reciclables, proveen de insumos para el autoconsumo a la asociación y beneficiarios. Las bases filosóficas que sustentan el modelo de intervención de la asociación están basadas en el respeto mutuo, la defensa de los derechos humanos, la promoción del autocuidado, el desarrollo de capacidades y el acompañamiento familiar.

\section{Diseño de investigación}

Las preguntas de investigación que guiaron el trabajo fueron: ¿cuál es el campo, las oportunidades y áreas de intervención del trabajo social en una asociación civil que atiende a jóvenes y adultos con alguna discapacidad?, y ¿qué significados, sentimientos y aprendizajes tienen algunos beneficiarios y personal (administrativos, voluntarios y docentes) sobre el modelo de intervención que tiene esta asociación?

\section{Objetivo General}

- Analizar los tipos de intervención que tiene el profesional de trabajo social con jóvenes y adultos con alguna discapacidad en una asociación civil en la ciudad de SCLC, y cómo se potencia la resiliencia de estas personas para su inserción social, familiar y laboral.

\section{Objetivos específicos}

- Analizar el funcionamiento de la asociación civil y el modelo de intervención que realiza con personas que presentan alguna discapacidad.

- Indagar las áreas de intervención del trabajo social en asociaciones que laboran con personas que tienen distintos tipos de discapacidades.

- Conocer algunos significados, sentimientos y aprendizajes de beneficiarios, docentes, administrativos y voluntarios que asisten a la asociación.

2 Esta sigla se utilizará para identificar la asociación civil donde se realizó la investigación, para respetar el anonimato y la confidencialidad de la información proporcionada. 
- Comprender de qué manera se potencia y apoya a los beneficiarios para lograr su resiliencia.

\section{Metodología}

La perspectiva metodológica utilizada fue de tipo cualitativa, con el apoyo de la Investigación-Acción-Participativa (IAP), (Balcázar, 2003). Este enfoque permitió analizar los tipos de intervención que pueden llevarse a cabo en una asociación civil que atiende a jóvenes y adultos que presentan alguna discapacidad. Durante la primera etapa se conoció el funcionamiento de los programas y el modelo de intervención de $A A$; en la segunda fase se recolectó información sobre los significados, sentimientos, aprendizajes/cambios de los beneficiarios, docentes, administrativos y voluntarios, poniendo énfasis en la forma en que se potencia a los beneficiarios para lograr la resiliencia y su integración a la sociedad.

La IAP facilitó la imnersión y el trabajo de campo para conocer la realidad social de la asociación, considerando que las personas con discapacidad y el personal que colabora son los protagonistas de la investigación, que interactúan a lo largo del proceso. La Federación Internacional de Trabajo Social señala que la metodología participativa "se centra en involucrar a las personas y las estructuras para hacer frente a desafíos de la vida y aumentar el bienestar. Hasta donde sea posible el trabajo social apoya el trabajo con y no para las personas" (FITS, 2014:1).

Promover la participación no es tarea fácil, menos si se trata de personas con discapacidades distintas que asisten en una asociación. En muchas ocasiones los beneficiarios experimentan baja autoestima y desconfianza, otros están acostumbrados a las políticas asistencialistas, lo que imposibilia el autodesarrollo de sus habilidades como lo señala Freire: "tienen el patrón metido en la cabeza y fatalísticamente aceptan su explotación..., lo difícil es convencerlos de su capacidad para participar en esfuerzos de autoayuda para mejorar su condición social" (Freire, 1970 en Balzázar, 2003:68).

Reforzar las fortalezas de los participantes lleva a un incremento en el conocimiento de sus capacidades personales y sus esfuerzos de autoayuda; es necesario motivarles en el proceso, sobre todo por sus vulnerabilidades y sus historias de exclusión/discriminación. Las barreras principales para colaborar en este tipo de proyectos son los temores e inhibiciones internalizadas sobre su estado de inferioridad o dificultad de desarrollo. Cuando están convencidas que su situación no se puede cambiar, promover el cambio es muy difícil. Por esto, es importante que los trabajadores sociales diseñen acciones para reforzar, estimular sus capacidades y habilidades, partiendo de sus intereses, sin enfocarse en las limitaciones que pudieran tener.

\section{Técnicas e instrumentos}

El trabajo de campo comprendió 170 horas de visita. Mediante procesos de observación, preguntas y escucha, se recabó información de primera mano con beneficiarios, trabajadores y voluntarios. Las técnicas utilizadas fueron: observación participante, diario de campo, entrevistas semiestructuradas y a profundidad. Durante el proceso investigativo se recopiló información mediante fotografías. Las guías de entrevistas orientaron la conversación con los participantes; las preguntas eran abiertas, detonadoras y específicas; fueron aplicadas de manera aleatoria, tomando al menos dos personas de cada área; se consideró la discapacidad del beneficiario y su motivación para participar.

En el diario de campo se registró lo observado durante toda la investigación, las fotografías captaron las reacciones y expresiones de su cuerpo y en las entrevistas quedaron grabadas sus percepciones, sentimientos y aprendizajes. Para recabar esta información se solicitó autorización a cada participante, señalando que se respetaría el anonimato y la confidencialidad de la misma, por ello se recurrió a pseudónimos. Las tres herramientas más el material documental fueron los recursos para la triangulación de la información y su posterior análisis.

\section{Análisis}

La perspectiva utilizada fue el análisis de contenido cualitativo, que consistió en una descripción fundamentada y objetiva de lo encontrado en la comunicación verbal y en las conductas observadas. Bernete (2014:194) señala que "es una metodología sistemática y objetivada porque utiliza procedimientos variables y categorías que responden a diseños de estudio y criterios de análisis, definidos y explícitos".

Durante el análisis se siguieron varios pasos: 1) identificación de códigos para descubrir y evidenciar el contenido oculto; es decir, conocer no sólo lo que se transmite verbal durante las entrevistas, sino todo aquello que pueda influir o condicionar el mensaje expreso; 2) transcripción textual de cada entrevista; 3) marcación con colores de los discursos, temas, comentarios y/o pensamientos más relevantes expresados por los participantes; 4) selección y agrupación de los códigos y categorías subrayadas, recortando las oraciones o discursos expresados por las personas entrevistadas; 5) organización de cada categoría mediante mapas gráficos, para definir operacionalmente y proceder a su redacción analítica. 


\section{HALLAZGOS Y DESCRIPCIÓN ANALÍTICA DE LAS PRINCIPALES CATEGORÍAS}

\section{Significados}

“...el proyecto que tenemos es un proyecto de vida para, para jóvenes con distintas discapacidades o capacidades distintas y para que ellos tengan una mejor calidad de vida, ese es el motivo por el cual se formó $A A^{\prime \prime}(A-G)$.

Dentro del trabajo social es sumamente importante tomar en cuenta las expresiones de las personas y el significado que dan a sus pensamientos, sentimientos y emociones. En la investigación se identificó lo que AA significa para beneficiarios, administrativos, docentes y voluntarios.

"Pues yo si siento que fuera mi familia, como que, pues, que significa mucho para mí. Si algún día me salgo de aquí me voy a deprimir muchísimo. Pues sí, siento que fuera otra casa, otro hogar y como que los chicos fueran mi familia, mis amigos" (P-T).

"En mi vida ha significado mucho, ha sido un cambio, ha sido para mí un despertar humano, también las ganas de seguir logrando mis sueños" (P-K).

Los beneficiados respondieron más con simbolismos, mencionaron que para ellos AA significa un corazón, algo liberal, como tener paz; utilizaron palabras como lindo, bonito y un lugar donde pueden hacer sus labores y aprender.

"A mmmm, bueno, es un corazón..." (B-T-Parálisis psicomotriz).

"AA significa para mí una asociación civil donde muchas personas con diferente discapacidad puedan hacer sus labores para independizarse, socializarse con sus amigos, colaborar con todo el equipo de aquí, y para mí la asociación es algo que realmente me trajo algo bonito, algo bueno de la vida" (B-I-Discapacidad visual).

Como se mencionó en párrafos anteriores, dentro de los principios del trabajo social está hacer valer los derechos del ser humano y la no discriminación, cuestiones que deben prevalecer siempre; se trata de un trabajo con una connotación ética, respetando la diversidad. AA es un proyecto de vida que brinda amor, respeto, cariño y valor a la persona; les ven como individuos útiles que pueden ofrecer mucho a la sociedad. "aquí se les brinda amor más que nada, sí, y bueno, independientemente de las actividades que tengan ¿no?, pero se les trata con respeto, con mucho cariño, sí, con abrazos, con besos, que sientan ellos que se les quiere, que no son una carga para nadie. Aunque en sus casas no los valoren, nosotros los valoramos aqui" (A-G).

"ahorita más, la intención es más generarles como esta cuestión de la productividad y de reflejar esta productividad a la sociedad ¿no?, que la sociedad vea que las personas con discapacidad son de igual de productivas como cualquier otra persona..." (A-J).

El modelo de intervención de la asociación genera empatía en las personas, es solidario y promueve el voluntariado, ofrece beneficios a los familiares con terapias, consejos y orientación. Algunos docentes explicaron que para las personas que acuden es un espacio de entretenimiento, convivencia y alegría, del que salen a su casa con nuevas actitudes y más felices.

"Yo siento que es un lugar excelente para que se escapen de todas esas cosas malas que viven dentro de sus casas, a lo mejor que pudieran estar feas, y aquí, como que tienen gente que los quieren mucho, los consentimos, trabajamos con ellos, jugamos, hacemos muchas cosas para que estén bien" (V-M).

\section{Sentimientos}

"Aquí es como tener paz interior en mi corazón y así [en] mi alma, como que me siento más liberal" (B-A- Parálisis psicomotriz)

Los profesionales de trabajo social deben tener presente los sentimientos de los usuarios, porque estos dan señales sobre el impacto, aprendizajes, cambios, sentimientos y emociones que experimentan; también, sobre las áreas de oportunidad o aspectos que se pueden mejorar. Algunos profesores y voluntarios expresaron sentir satisfacción y felicidad por laborar allí, ya que aprenden más de lo que sienten que enseñan:

"Mucha, mucha satisfacción, me da alegrías en el momento que los veo, si se ríen, que gozan, pero además, mucha satisfacción de ver la felicidad que se les brinda, la alegría que ellos demuestran al estar aquí, eso es lo que me da más gusto y digo: ¡vale la pena mi vida!" (A-G). 
"Me entienden, me hacen sentir bien, esas cosas llenan mucho... Me gustaría hacer más por ellos" (P-T).

"Estoy muy contenta por todo lo que ellos me enseñan" (V-M).

"Personalmente, es una oportunidad de ser feliz trabajando en lo que me gusta" (P-J).

Algunas expresiones de felicidad, alegría y ánimo se pudieron constatar a través de los rostros y postura corporal de los beneficiados al responder la entrevista. Algo valioso es que lo expresaron con toda libertad, sin cohibiciones. Una herramienta indispensable en la práctica del trabajo social es la observación, ésta nos permite constatar lo que se dice oralmente y lo expresado con el cuerpo.

"Yo me siento contento, sí, porque ya se siente uno así, con ánimo" (B-T-Parálisis psicomotriz).

"Toy feliz, muy contenta poque tengo amigos como J., A., O., J., T., L., M., N., todos. Vengo contenta poque tengo amigos, canto, bailo y toy feliz" (B-H-Síndrome de Down).

"Es algo que realmente me trajo algo bonito, algo bueno de la vida" (B-I-Discapacidad visual).

\section{Aprendizajes y cambios}

"De tareas, e aspender a escribí. Yo me pedí cocina, me pedi postes, pastele" [De tareas, y aprender a escribir. Yo me aprendí a cocinar, me aprendí postres, pasteles] (B-H. Síndrome de Down).

Los entrevistados comentaron algunos cambios y aprendizajes que han experimentado desde que asisten a la asociación, desde su rol de beneficiario, docente, voluntario y/o administrativo.

"Bueno si he cambiado mucho..., pos en otras escuelas, pues sí, (suspiro) era yo un poco tremendo, más con las mujeres, ahora he cambiado mucho, ya respeto. Además, antes la hortaliza no lo, no podía yo hacer, ahora ya sé, ya aprendo, ya veo como se hace y un poco la cocina, repostería lo que es repostería y todo, me gusta" (B-A- Parálisis psicomotriz).

"Apendí que sí lo puedo hace solita una tota, un jugo. Me gusta cocina y ayudale a mi mamá" (B-H-Síndrome de Down).

"He aprendido de todo, la verdad, he aprendido a escribir en braille, porque yo no muy sabía, he aprendido a hacer los ejercicios, también lo que es calentamiento, he aprendido cómo debemos ensayar para poder actuar y poder socializarnos con los amigos" (B-I-Discapacidad visual).

Los profesionales de trabajo social deben analizar la conjunción de los componentes: cognición, afecto y comportamiento, para determinar el aprendizaje y cambios que pueda tener una persona. Quienes trabajan en AA están aprendiendo en la cotidianidad, tienen la posibilidad de repensar su vida personal y familiar, esto impacta de manera directa en ellos/as, en sus aprendizajes y en su vida personal:

"Ellos nos han enseñado, aprendemos mucho más nosotros de ellos que ellos de nosotros... en la vida tienes muchas dificultades no solamente por tu, por un hijo con discapacidad, hay otros problemas en tu hogar, hay otros problemas en tu vida, que comparado con lo que tienes dices: bueno no vale la pena de que, de que tú te mortifiques por cosas materiales..." (A-G).

Después de realizado el trabajo de investigación, podemos señalar que AA ha impactado de manera positiva en la vida de los beneficiarios, trabajadores y/o voluntarios, así lo expresaron en diversos momentos en las entrevistas:

"Cuando ya llevaba unos meses me sentí como en familia, más que todo me sentía útil a la sociedad y todo, me siento bien" (B-A- Parálisis psicomotriz).

"Me gusta estar aquí porque me gusta cantar, hacer mis manualidades, como hacer bufandas, tejer, el teatro y también lo que me gusta es lo que es fisioterapia" (B-I. Discapacidad visual).

En cuanto al avance hacia procesos de resiliencia, se pudo observar la forma en cómo AA apoya a los beneficiarios, los motiva, desarrolla algunas habilidades y capacidades para que alcancen poco a poco su independencia. Anguiano (2009) señala que la resiliencia es más que la aptitud de resistir a la destrucción preservando la integridad en circunstancias difíciles, es también la aptitud-proceso de reaccionar positivamente frente a las dificultades y la posibilidad de construir con base en las fuerzas propias del ser humano. "No es sólo sobrevivir a pesar de todo, sino tener la capacidad de usar la experiencia sobre las situaciones adversas para proyectar el futuro" (2009:76-77).

"En mi familia me dicen que todo lo que hago está muy bien, que le eche muchas ganas, que eso me va a 


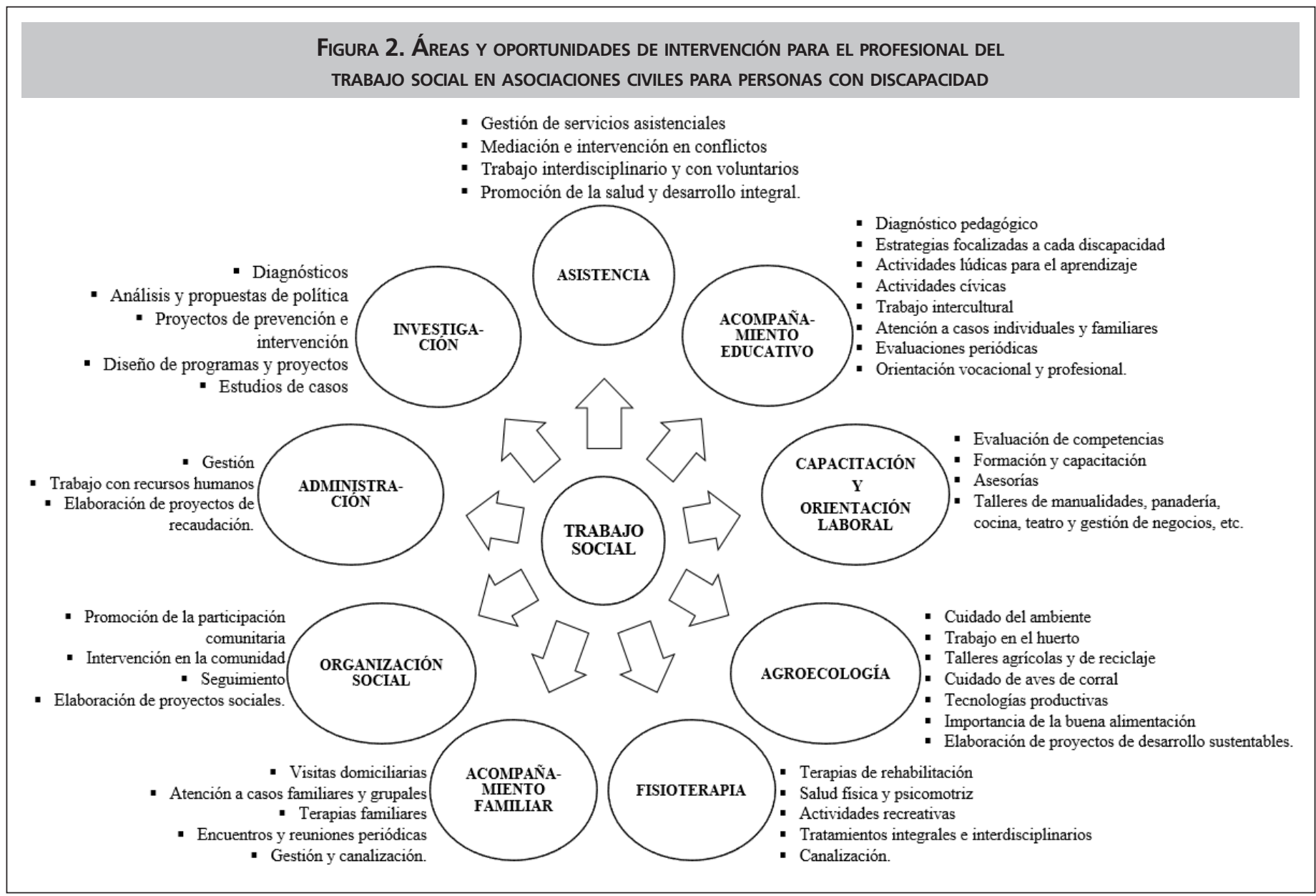

Fuente: elaboración propia.

servir de mucho, como para poder independizarme, más que nada" (B-I-Discapacidad visual).

"Trabajo en una carpintería, pues, lo que es de así de madera, lijar y todo, levantar madera, así, cosas así que sean malo los compongo, y así. En AA aprendí hacer pizzas y me gusta hacer las pizzas que pide la gente y llevárselas" (B-A-Parálisis psicomotriz).

Cuando las personas beneficiadas señalan poder realizar actividades diarias sin ayuda y gracias a los aprendizajes que han tenido en la asociación, están logrando mayor independencia, esto indica que están caminando hacia la resiliencia.

\section{CONCLUSIONES Y PROPUESTAS}

La intervención del trabajo social en México es sumamente compleja debido a la diversidad y multiculturalidad existente en el país y los diversos aspectos de índole político, económico y social que confluyen en él. Ante esta realidad, se debe fortalecer la identidad profesional, utilizando metodologías científicas, planificadas, justas y éticas. En este sentido,
Muyor (2011), señala que este trabajo debe hacerse en, con, por y para la sociedad, asumiendo que se trata de una tarea profundamente comprometida y desafiante; exponente de un ejercicio profesional que enfatice el protagonismo de la ciudadanía y los principios que sustentan el compromiso con la justicia social, la promoción de la igualdad y equidad para construir una sociedad que acepte y promueva la diversidad y el respeto por los derechos humanos.

Stainton; Chenoweth y Bigby (2010) advierten que todo esto no es fácil, no solo se requieren nuevas herramientas técnicas, sino una mirada crítica sobre cuáles son los valores centrales de la profesión y cómo pueden expresarse de mejor manera en la práctica profesional y en las políticas públicas y sociales. Actualmente no se reconoce la diversidad de ámbitos de los profesionales del trabajo social en donde pueden tener injerencia; por lo general laboran en hospitales, reclusorios y escuelas gubernamentales, realizando especialmente cuestiones administrativas, dejando de lado una multiplicidad de campos de acción (ver figura 2).

Se ha avanzado mucho en el mundo de la discapacidad en las últimas décadas, pero hay que seguir prosperando 


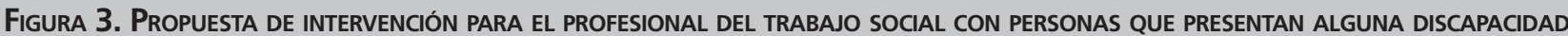

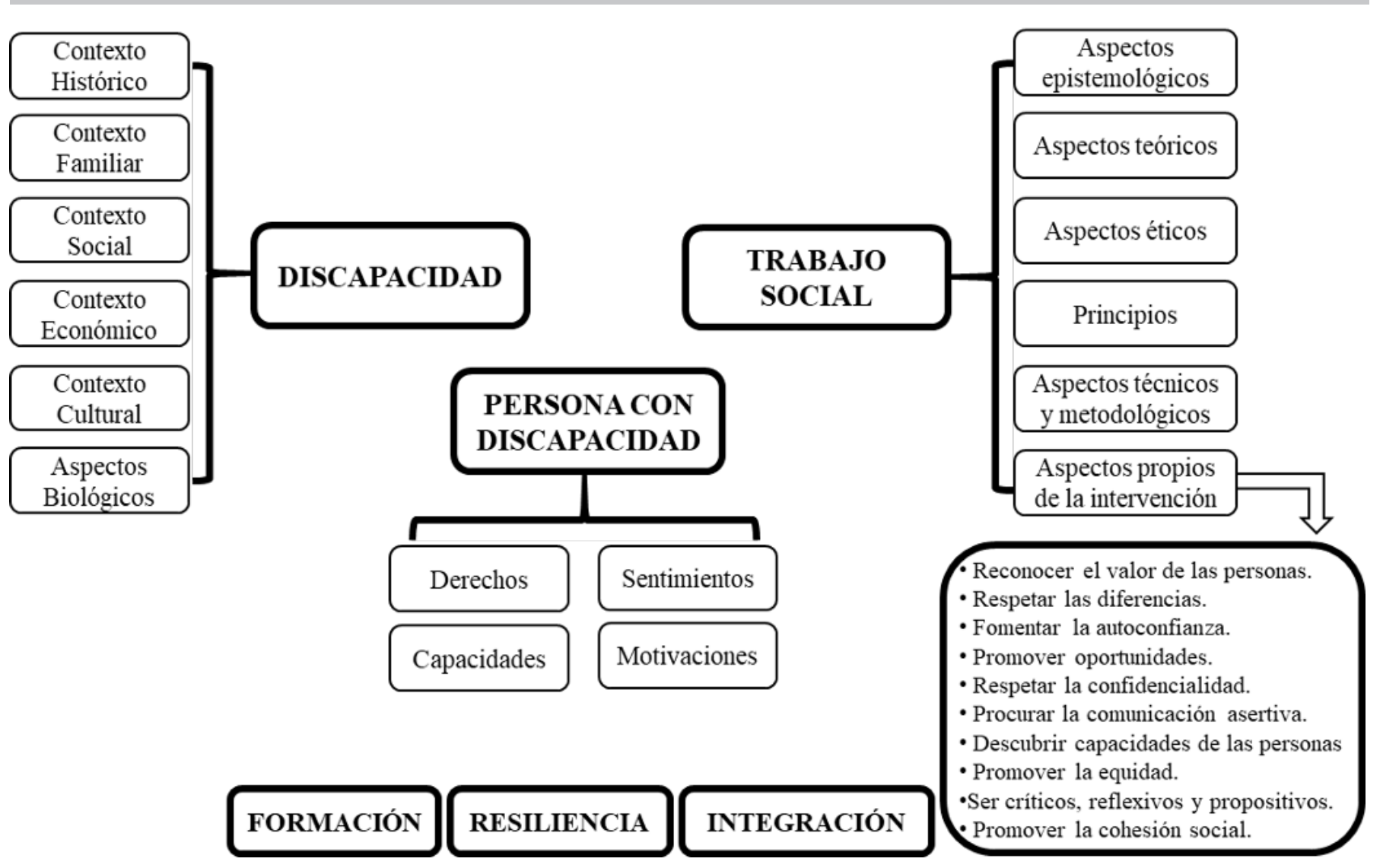

Fuente: elaboración propia.

(Verdugo, 2009). El trabajo debe hacerse con más planificación, concertación y evaluación. No se trata de desarrollar solo procesos y acciones, sino añadir reflexión, análisis, preparación profesional, competencia investigadora y trabajo multi e interdisciplinario.

Esta investigación subraya el compromiso del profesional del trabajo social con el ser humano y la lucha por sus derechos, principalmente de equidad y justicia. Luego de analizar un conjunto de referentes teóricos, metodológicos, epistemológicos, éticos, técnicos y propios de la profesión del trabajo social, desarrollamos una propuesta de intervención para la atención de personas que presentan alguna discapacidad.

La propuesta toma en cuenta el valor de las personas, el respeto a las diferencias, a la diversidad, confidencialidad y a la confianza; descubrir sus capacidades y fomentar la autoconfianza; promover oportunidades, la equidad y la cohesión social; procurar la comunicación asertiva, ser críticos, reflexivos y propositivos. Toda intervención del profesional del trabajo social con personas que presentan alguna discapacidad debe tener presente el contexto histórico, social, familiar, económico, cultural y los aspectos biológicos del ser humano; así se concibe a la persona con discapacidad como un individuo con derechos, sentimientos, motivaciones y capacidades. Los principios básicos en los que se sustenta la propuesta son: integración, formación y resiliencia, que se convierten en los ejes principales de la intervención:

a) La intervención como campo de actuación. Los profesionales del trabajo social deben ofrecer sus servicios por el respeto a la dignidad de las personas, considerando a cada cual como un sujeto de acción y no como objeto susceptible de caridad.

b) Tomar como punto de partida sus derechos, capacidades, potencialidades y deberes. No dejar de lado el contexto, los aspectos biológicos, sus motivaciones y sentimientos.

c) La resiliencia como objetivo a alcanzar. La propuesta es la búsqueda de la transformación personal, familiar y comunitaria, tomando en cuenta como ente articulador del proceso al profesionista en trabajo social. Es importante mantener la mirada en la dignidad de las personas y en los principios de la profesión, con ello 
presente es posible desarrollar intervenciones para promover la resiliencia.

Los resultados de esta investigación indican que desde el trabajo social se pueden encaminar procesos de resiliencia social de largo alcance. Si utilizamos el modelo de la diversidad y enfocamos la intervención profesional hacia el desarrollo de capacidades valorando los derechos humanos de las personas con alguna discapacidad, teniendo presente el contexto histórico, social, familiar, económico, cultural, sus aspectos biológicos, concibiéndolos como individuos con sentimientos, emociones, expectativas y motivaciones; se pueden lograr avances significativos en sus condiciones de vida y en su integración activa y constructiva en la sociedad.

\section{REFERENCIAS}

Abberley, P. (2008). El concepto de opresión y el desarrollo de una teoría social de la discapacidad. En L. Barton (Ed.), Superar las barreras de la discapacidad, (pp. 34-50). Madrid: Morata.

Ander-Egg, E. (2008). Los trabajadores sociales en el contexto de un mundo globalizado. Condiciones y cualidades. Universidad Autónoma de Nuevo León-FENEETS. México: Impresiones Arte Ediciones, S.A. de C.V.

Anguiano, A. (2009). Reflexiones sobre tutoría práctica profesional, proyectos sociales y resiliencia. (2ªdición). México: Amate editorial.

Badilla, H. (1999). Para comprender el concepto de resiliencia. Revista costarricense de trabajo social, 9, 22-29. Recuperado de https://revista.trabajosocial.or.cr/index.php/ revista/article/view/229/255

Balcázar, F. (2003). Investigación acción participativa (IAP): Aspectos conceptuales y dificultades de implementación. Fundamentos en humanidades, 2 (8), 59-77.

Barranco, M. (2004). La intervención en trabajo social desde la calidad integrada. Alternativas, Cuadernos de trabajo social, 12, 79-102, Universidad de Alicante, España. Recuperado de https://rua.ua.es/dspace/bitstream/10045/5592/1/ALT 12 05.pdf

Barton, L. (1998). Sociología y discapacidad: algunos temas nuevos. En L. Barton (Ed.), Discapacidad y sociedad (pp. 19-33). España: Fundación Dialnet-Universidad de La Rioja.

Bermúdez, C. (2011). Intervención social desde el trabajo social: un campo de fuerzas en pugna. Prospectiva, N 16, 1-13. Recuperado de http://revistaprospectiva.univalle. edu.co/index.php/prospectiva/article/view/1164/1284
Bernete, F. (2014). Análisis de contenido. En A. Lucas y A. Noboa (Ed.), Conocer lo social: Estrategias, técnicas de construcción y análisis de datos (pp. 221-261). Madrid. Editorial Fragua.

Celia, M. (2009). Teoría de la intervención en trabajo social. Universidad de Brasil. Recuperado de http://dns.ts.ucr.ac. cr/binarios/pela/pl-000048.pdf

Consejo Nacional de Población (2017). Índice de marginación. México: CONAPO. Recuperado de http://www.conapo.gob.mx/es/CONAPO/Indices de Marginacion Publicaciones

Córdoba, P. (2008). Inclusión y ambiente. Discapacidad y exclusión social: propuesta teórica de vinculación paradigmática. Panamá: Centro de Estudios Latinoamericanos Justo Arosemena/Consejo Latinoamericano de Ciencias Sociales. Recuperado de https://bibliotecavirtual.clacso. org.ar/Panama/cela/20120717104229/discapacidad.pdf

Corvalán, J. (1996). Los paradigmas de lo social y las concepciones de intervención en la sociedad. CIDE, Documentos, N4, Santiago: Universidad de la República Uruguay-Red Académica Uruguay. Recuperado de http://www.rau.edu. uy/fcs/dts/Mip1/corvalan.pdf.

De Lorenzo, R. (2014). Discapacidad, sistemas de protección y trabajo social. Cap. 7, pp.363-429. Madrid: Editorial Alianza.

De Munford, R. y Bennie, G. (2015). Discapacidad de aprendizaje y trabajo social. En: James D. Wright (Ed.), Enciclopedia Internacional de Ciencias Sociales y del Comportamiento, segunda edición, Vol 13, (pp. 684-689). Oxford: Elsevier. Recuperado de https://www.researchgate.net/publication/304191128 Learning Disability and Social Work

Escartín, M. (1998). Manual de trabajo social. Madrid: Editorial Aguaclara.

Estrada, V. (2010). Resignificar la formación académica y la intervención profesional en lo social. Trabajo Social, 12, 55-64. Recuperado de https://revistas.unal.edu.co/index. php/tsocial/article/view/18559/19463

Fernández, S. (2017). La teoría en la intervención social. Modelos y enfoques para el trabajo social del siglo XXI. Acción social. Revista de política social y servicios sociales, 1 (1), 9-43. Recuperado de https://socialmurcia.files.wordpress.com/2016/11/accion-social-1-2-2017.pdf

Federación Internacional de Trabajo Social (2014). Definición global del trabajo social. Federación Internacional de Trabajo Social. Australia: FITS. Recuperado de https://www. cgtrabajosocial.es/DefinicionTrabajoSocial

Humphrey, F. (2013). ¿En qué consiste la intervención del trabajo social? Trad. Xóchitl Gutiérrez Cervantes. Recupe- 
rado de http://www.ehowenespanol.com/consiste-intervencion-del-social-sobre 51002/

INEGI (2016). Estadísticas a propósito del día internacional de las personas con discapacidad. México: INEGI.

(2015a). Anuario estadístico y geográfico. México: INEGI. (2015b). Las personas con discapacidad en México, una visión al 2010. México: INEGI. Recuperado de http:// www.inegi.org. $\mathrm{mx} / \mathrm{prod}$ serv/contenidos/espanol/ bvinegi/productos/censos/poblacion/2010/discapacidad/702825051785.pdfConsultado

(2014). Directorio nacional de asociaciones de y para personas con discapacidad. Tomo II. México: INEGI.

(2013). Estadísticas a propósito del día internacional de las personas con discapacidad. México: INEGI.

(2012). Clasificación de tipo de discapacidad-histórica. México: INEGI.

(2010). Censo de población y vivienda. México: INEGI. Recuperado de http://www3.inegi.org.mx/sistemas/TabuladosBasicos/Default.aspx?c=27303\&s=est

López, C. y Seco, E. (2005). Discapacidad y empleo en España: su visibilidad. INNOVAR, Revista de ciencias administrativas y sociales. 26 (15), 59-72.

Malo, M. (2003). Las personas con discapacidad en el mercado de trabajo español. Revista del Ministerio de trabajo y asuntos sociales. 46, 99-126. Recuperado de http://dialnet.unirioja.es/servlet/articulo? codigo $=772584$

Martínez, J. (2013). Otro mundo es posible y necesario ¿Cómo lograrlo? México: La Casa del Mago.

Muyor, J. (2011). La (con)ciencia del trabajo social en la discapacidad: Hacia un modelo de intervención social basado en derechos. Revista de Trabajo Social y Acción Social, 49, 9-33.

Ortega, M. (2015). Trabajo social como transdisciplina: hacia una teoría de la intervención. Revista de Epistemología de Ciencias Sociales. Facultad de Ciencias Sociales, Universidad de Chile, 54, 278-289. Recuperado de www.moebio. uchile.cl/54/ortega.html

Pantano, L. (2010). La discapacidad como problema social. Argentina: Editorial Eudeba. Recuperado de http://www.la-linterna.cl/accesible/estado/comunidad.html

Programa de las Naciones Unidas para el Desarrollo (2015). Índice de desarrollo humano en México para las entidades federativas, México 2015. México: PNUD.

Schalok, R. (1999). Hacia una nueva concepción de la discapacidad. III Jornadas científicas de investigación sobre personas con discapacidad. Universidad de Salamanca, España.

Schalok, R. y Verdugo, M. (2007). El concepto de calidad de vida en los servicios y apoyos para personas con discapacidad intelectual. Revista Española sobre Discapacidad Intelectual, 38 (4), 224, 21-36.

Stainton, T.; Chenoweth, L. y Bigby, C. (2010). Social work and disability: An uneasy relationship. Australian Social Work. 63 (1), 1-3. Australia: Routledge, Taylor \& Francis Group.

Suárez, E. (2003). Una concepción latinoamericana: La resiliencia comunitaria. En Melillo, A. y Suárez, E. (Ed.), Resiliencia. Descubriendo las propias fortalezas (pp. 67-82). Buenos Aires: Paidós. Recuperado de https://dialnet.unirioja.es/servlet/libro?codigo $=366404$

Tello, N. (2014). Trabajo social contemporáneo: tres grandes problemas. I Congreso internacional de facultades y escuelas de trabajo social. España: Editorial Universitas. Recuperado de http://neliatello.com/docs/trabajo-social-contemporaneo-tres-grandes-problemas.pdf

Verdugo, M. (2009). Calidad de vida, I+D+i y políticas sociales. Revista Española sobre Discapacidad Intelectual, 40(1), 229, 5-21.

Villafuerte, D. y García, M. (2014). Tres ciclos migratorios en Chiapas: interno, regional e internacional. Red Internacional de Migración y Desarrollo. Revista Migración y Desarrol/o, 1 (22), 3-37. Recuperado de http://www.scielo. org. mx/pdf/myd/v12n22/v12n22a1.pdf

Villalba, C. (2011). El enfoque de resiliencia en trabajo social. Universidad Pablo de Olavide. España: Fundación Dialnet. Recuperado de https://dialnet.unirioja.es/descarga/articulo/2002483.pdf 